\title{
Immobilisation hypercalcaemia complicating polyneuropathy in adolescent boys
}

\author{
TJ WALLS, B ASHWORTH, M SAUNDERS
}

From the Department of Neurology, Middlesbrough General Hospital and The University Department of
Medical Neurology, Northern General Hospital, Edinburgh, UK

SUMMARY Two boys who were immobilised with peripheral neuropathy developed hypercalcaemia. It is suggested that hypercalcaemia aggravated the muscle weakness as well as producing systemic upset. The hypercalcaemia was controlled with corticosterioids which had to be continued over several months. A satisfactory remission of the disease occurred in both cases. The hypercalcaemia was attributed to immobility in young people with rapid calcium turnover in bone.

Immobilisation hypercalcaemia is an unusual condition which occurs predominantly in adolescent males. ${ }^{2}$ The majority of reports describe it in association with trauma and fractures. ${ }^{3-11}$ We report two adolescent males with peripheral neuropathy who developed this syndrome, which resulted in systemic malaise and increased disability.

\section{Case 1}

An 11-year-old schoolboy presented with a history of generalised malaise, weight loss and an unproductive cough. Two weeks after these symptoms began he developed paraesthesiae in his hands and feet, and then progressive weakness. This began in one hand and later became generalised, involving proximal and distal muscle groups of all limbs. There was truncal weakness, but no respiratory embarrassment and no cranial nerve deficit. He was areflexic but there was no sensory loss. Over the next five days his power diminished but at his weakest he was able to stand unaided although he could not walk (week 3, fig 1). Over the course of the next few weeks he progressively improved and he was discharged from hospital at the end of 5 weeks, able to walk slowly and unsteadily, but without assistance. A peripheral eosinophilia ( $0.63 \times 10 \%$ 1) found on admission, later resolved. The serum antibody titre was $1 / 640$ against mycoplasma pneumoniae. The CSF contained no cells and the protein content was $0.54 \mathrm{~g} / 1$ (N $<0.4 \mathrm{~g} / \mathrm{l})$. Urinary prophyrins were not detected. Motor nerve conduction velocities were reduced $(35 \mathrm{~m} / \mathrm{s}$ in the right common peroneal nerve). The diagnosis was the Guillain-Barré syndrome secondary to a mycoplasma

Address for reprint requests: Dr TJ Walls, Newcastle General Hospital, Westgate Rd, Newcastle upon Tyne, NE4 6BE, UK.

Received 31 January 1984 and in revised form 16 May 1984. Accepted 21 May 1984 infection. Hypercalcaemia was noted during week 5, and he vomited on one occasion at that time. With increasing mobility, the serum calcium seemed to be falling and when first discharged from hospital he had no symptoms suggesting hypercalcaemia. He was re-admitted at the end of week 6 with a 48 hour history of persistent vomiting, general malaise and markedly increased weakness. By the time of admission, he was unable to stand, and by 3 days later, he was unable to sit in bed unaided and had developed a bilateral wrist and foot drop. The serum calcium levels at that time are illustrated in fig 1; inorganic phosphate was $0.96 \mathrm{mmol} / \mathrm{l}$, alkaline phosphatase $109 \mathrm{IU} / \mathrm{l}$ (N 35$100 \mathrm{IO} / \mathrm{l})$, parathormone undetectable, serum thyroxine normal. Bone radiographs showed no changes of hyperparathyroidism and a chest radiograph was normal. The

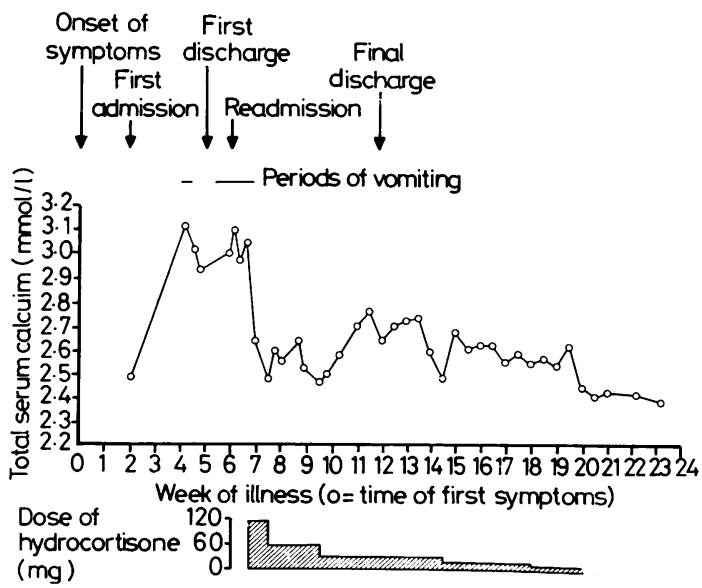

Fig 1 Serum calcium in relation to course ö illness and steroid therapy. 
Table 1 Functional disability of patient 1

\begin{tabular}{cl}
\hline Week & Level of functional disability \\
\hline 0 & Normal \\
2 & Mild generalised muscle weakness. Unable to run \\
3 & Able to stand but not to walk \\
5 & Walking slowly and unsteadily without assistance \\
6 & Unable to stand \\
7 & Unable to sit up in bed unaided, bilateral wrist and foot \\
9 & drop \\
12 & Able to sit up in wheelchair, unable to feed himself \\
18 & Able to take a few steps with assistance \\
24 & Walking slowly independently, severe wrist and foot drop \\
40 & Walking independently with waddling gait, foot and wrist \\
& drop persist \\
\hline
\end{tabular}

Mantoux test was positive at $1 / 1000$ compatible with his previous immunisation. The CSF again contained no cells, the protein content had risen to $1 \cdot 22 \mathrm{~g} / \mathrm{l}$.

He became progressively weaker and developed profuse vomiting. Treatment with hydrocortisone $120 \mathrm{mg}$ daily was begun and was an immediate improvement in his general condition. The vomiting stopped and the serum calcium returned to normal within forty-eight hours. The subsequent course of his illness is shown in fig 1 and detailed in table 1 . Each reduction in the dose of hydrocortisone was followed by a rise in the serum calcium, although never to levels which produced symptoms. When mobility increased the serum calcium fell, allowing further reductions in the steroid dose to be made. Even when the hypercalcaemia resolved, he was left with a severe flaccid tetraparesis requiring inpatient care until the end of week 12 . He slowly improved, and by the end of week 14 was able to take a few steps with the aid of one person. Independent walking however was not achieved until the end of week 20 and it was at this stage the steroids could be completely withdrawn. At the time of writing, 12 months after the initial presentation, he remains normocalcaemic but still has a severe wrist and foot drop which are improving only slowly.

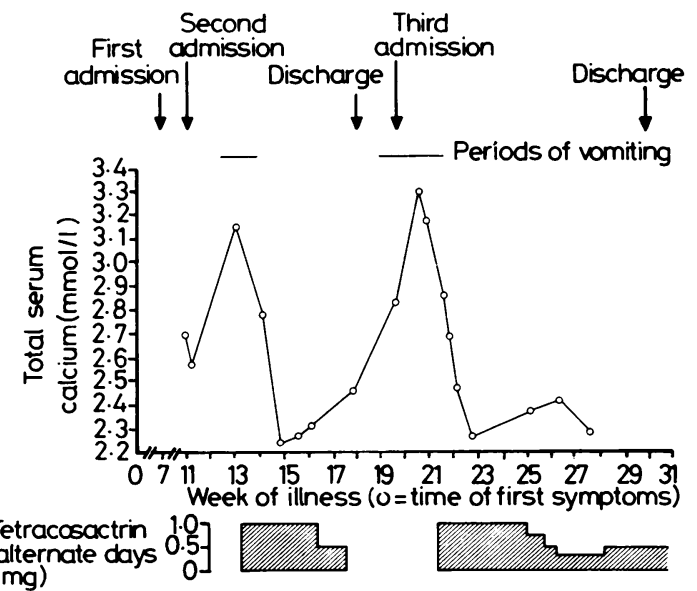

Fig 2 Serum calcium in relation to course of illness and steroid therapy.
Case 2

A 14-year-old boy presented with a 7 week history of weakness of both arms, more marked initially on the left than the right. Five weeks before being seen, he had developed difficulty in walking upstairs and in rising from a chair. By the time of presentation he showed generalised weakness in his arms and legs which was symmetrical and involved all muscle groups. There was some truncal weakness, but no cranial nerve abnormality or respiratory disturbance. The knee jerks were obtained but he was otherwise areflexic and there was no sensory loss.

The CSF contained no cells and the protein content was $0.48 \mathrm{~g} / \mathrm{l}$. Motor nerve conduction velocities were slowed $(27 \mathrm{~m} / \mathrm{s}$ in the right median nerve) with prolonged distal latencies $(7.8 \mathrm{~m} / \mathrm{s}$ in the right median nerve). Electromyography revealed a reduced interference pattern but no evidence of active denervation. There were no porphyrins in his urine and a Mantoux test was positive. Viral serology was negative. He was thought to have an inflammatory polyneuropathy although the prolonged time course suggested that this was a chronic demyelinating polyneuropathy rather than the Guillain-Barré syndrome. $\mathrm{He}$ continued to deteriorate and was readmitted four weeks after his first admission (week 11, fig 2). At that time he was able to walk only with considerable support and there was marked generalised weakness in his arms. He had been confined to bed at home for about two weeks. On admission, his serum calcium was $2.7 \mathrm{mmol} / \mathrm{l}$, its fluctuation with the course of his illness can be followed in fig 2 , his functional disability is summarised in table 2 . The CSF protein content had risen to $1.15 \mathrm{~g} / \mathrm{l}$ and there were no cells. His weakness increased further and by the end of week thirteen he was unable to make any active movements with his arms against gravity or stand up and he developed persistent vomiting. The serum calcium rose. Treatment with tetracosactrin was followed by a rapid fall in the serum calcium cessation of vomiting and improvement in his muscle power so that by the end of week 16 he was feeding himself. The steroid was progressively reduced, and by the end of week 18 he was sufficiently well to be discharged home, on no treatment.

At home, the vomiting soon returned and he became progressively weaker. By the middle of week 19 he was again unable to feed himself and the serum calcium had risen to $3.3 \mathrm{mmol} / \mathrm{l}$. At the time of the highest serum calcium, parathormone was $0.25 \mu \mathrm{g} / \mathrm{l}(\mathrm{N}<0.6 \mu \mathrm{g} / \mathrm{l})$, the

Table 2 Functional disability of patient 2

\begin{tabular}{cl}
\hline Week & Level of functional disability \\
\hline 0 & Normal \\
2 & Difficulty climbing stairs or rising from a chair \\
7 & Marked weakness in arms, proximal weakness in legs \\
11 & No useful function in arms, walking with support only \\
13 & Severe generalised weakness, no useful limb function \\
15 & Feeding himself \\
18 & Mobile around ward, good function in arms \\
20 & Unable to walk or feed himself \\
23 & No useful function in arms, able to stand with help \\
24 & Feeding himself \\
27 & Mobile around ward \\
29 & Walking slowly but steadily no limit at own pace \\
78 & Minimal upper and lower limb girdle weakness \\
\hline
\end{tabular}


alkaline phosphatase level was $87 \mathrm{U} / \mathrm{l}$ (N 20-85 U/l), there was no renal impairment and thyroid function tests were normal. The serum calcium was temporarily depressed by an injection of $50 \mathrm{IU}$ calcitonin but returned to its previous level within twenty-four hours. Tetracosactrin therapy was resumed and he responded well. The serum calcium returned to normal and remained so although steroids had to be continued for a total of six months to maintain it. By week 24 he was again able to feed himself, by week 27 he was walking unsteadily unaided and has continued to improve since. Eighteen months from the onset of his illness there was only slight weakness of movements at the hip girdle and shoulder girdle.

\section{Discussion}

Extensive investigation of both patients failed to reveal any cause of their hypercalcaemia other than immobility. Hypercalcaemia may occur during prolonged immobilisation in any condition associated with increased bone turnover.' In adults, Paget's disease, carcinoma and thyrotoxicosis may be associated with hypercalcaemia if the patient is immobilised and in adolescents a specific syndrome of immobilisation hypercalcaemia is recognised. ${ }^{2}$

The condition was first described by Albright et $a l,{ }^{3}$ in 1941 . Several characteristic predisposing factors emerge from a study of later reports. ${ }^{4-11}$ The affected patients have all been boys between the ages of nine and fifteen years apart from the case described by Mason ${ }^{5}$ of a 22-year-old woman. Most patients have sustained fractures, often multiple, of their long bones requiring prolonged periods of immobilisation. One patient, that of Berliner et al ${ }^{8}$ developed the syndrome as a consequence of extensive burns, again requiring prolonged bed rest.

We have been unable to find any report of the development of this syndrome in patients with peripheral neuropathy although it was recognised many years ago that children immobilised by acute paralytic poliomyelitis occasionally develop hypercalcaemia. ${ }^{31213}$

In the healthy individual there is a balance between the resorption and the formation of bone which is influenced by age, nutritional and hormonal factors as well as the degree of physical activity. Osteoblastic activity is thought to be stimulated by mechanical stress. If such stress is removed by immobilisation then bone formation is reduced, leaving a relative excess of bone destruction causing the release of calcium into the extracellular fluid. Under normal circumstances, this increase in extracellular calcium concentration is compensated for by increased urinary calcium excretion maintaining normal serum calcium concentrations. Normal adult volunteers develop increased urinary calcium excre- tion two to three days after the onset of enforced immobilisation which increases to a peak four weeks later, remaining at this peak level until two to three weeks after remobilisation occurs when it begins to fall again. ${ }^{14}$ Similar patterns have been observed in adults immobilised by fractures ${ }^{15}$ and by poliomyelitis. ${ }^{12}$ At times of high bone turnover, any sudden reduction in osteoblast activity causes massive release of calcium into the extracellular fluid which overwhelms renal excretion, hypercalcaemia follows which in itself impairs renal excretion of calcium and sodium and water absorption from the proximal renal tubule. The serum calcium therefore progressively rises in the potentially disastrous spiral of disequilibrium hypercalcaemia. ${ }^{1}$

When hypercalcaemia is secondary to immobilisation, programmes of assisted weight bearing should be instituted when practicable, but if these are insufficient to reduce the serum calcium to normal then steroids or calcitonin are the most effective form of treatment. " Both our patients responded dramatically to small doses of steroids, with immediate cessation of symptoms. Prolonged treatment however was necessary and when steroids were withdrawn early (case 2), rebound symptomatic hypercalcaemia was associated with a temporary increase in weakness which resolved when steroids were re-introduced. In case 1 , there was marked permanent increase in weakness when symptomatic hypercalcaemia occurred, which did not resolve when the serum calcium was reduced to normal. This may have been due to axonal damage as there was no change in the nerve conduction velocities following his deterioration. The patient's functional recovery was considerably delayed and his residual deficit may be permanent.

Controlled trials have failed to demonstrate any therapeutic benefit from steroid treatment in the Guillain-Barré syndrome and have even suggested that such treatment may increase eventual functional disability. ${ }^{16}$ The prolonged evolution of the weakness in case 2 suggested that he had a more chronic inflammatory polyneuropathy. It is generally accepted that a significant proportion of patients with this condition respond to treatment with steroids. ${ }^{17}$ There are however well documented cases with the same syndrome who do not respond to steroid treatment. ${ }^{1819}$

There are few records of serum calcium levels among the reports of chronic inflammatory neuropathies in the literature. Where the serum calcium level is documented it is persistently normal. We have found no record of hypercalcaemia associated with symptomatic relapse in this condition and no description of functional deterioration in patients with the Guillain-Barré syndrome associated with 
hypercalcaemia. From our experience we feel that immobilisation hypercalcaemia is an indication for steroid therapy in both these conditions. We suggest that all patients immobilised at times of increased bone turnover should have their serum calcium monitored. Treatment should be given at an early stage and may need to be continued over a prolonged period.

Immobilisation hypercalcaemia is not a benign entity. It may be associated with relatively nonspecific symptoms initially but if left untreated the patient may go on to develop fits, encephalopathy or may even die.? In the past, it has been confused with hyerparathyroidism and has led to unnecessary surgical exploration of the neck. ${ }^{3}$ In both of our cases, it significantly increased the duration of their functional disability. In case 1 , it appeared to cause irreversible worsening of the peripheral neuropathy.

We thank Drs D Gardner-Medwin and CA Hardisty for advice about case 1 . Patient 2 was referred by $\mathbf{M r}$ B Dean.

\section{References}

' Hosking DJ. Disequilibrium hypercalcaemia. Br Med J 1983;286:326-7.

2 Wolf AW, Chiunard RG, Riggins RS, Walter RM, Depner T. Immobilisation hypercalcaemia. A case report and review of the literature. Clin Orthop 1976;118: 124-9.

${ }^{3}$ Albright F, Burnett $\mathrm{CH}$, Cope Q, Parson W. Acute atrophy of bone (Osteoporosis) simulating hyperparathyroidism. J Clin Endocrinol 1941;1:711-6.

${ }^{4}$ Dodd K, Graubarth H, Rapoport S. Hypercalcaemia nephropathy and encephalopathy following immobilisation. Paediatrics 1950;6:124-30.

5 Mason AS. Acute osteoporosis with hypercalaemia. Lancet 1957;272:911-2.
${ }^{-}$Halvorsen S. Osteoporosis, hypercalcaemia and nephropathy following immobilisation of children. Acta Med Scand 1954;149:401-8.

${ }^{7}$ Hyman LR, Boner G, Thomas JC, Segar WE. Immobilisation hypercalcaemia. Am $J$ Dis Child 1972; 124: 723-7.

${ }^{8}$ Berliner BC, Shenker IR, Weinstock MS. Hypercalcaemia associated with hypertension due to prolonged immobilisation. (An unusual complication of extensive burns). Paediatrics 1972;49:92-6.

' Lawrence GD, Loeffler RG, Martin LG, Connor TB. Immobilisation hypercalcaemia. J Bone Joint Surg 1973; 55-A:87-94.

${ }^{10}$ Henke JA, Thompson NW, Kaufer H. Immobilisation hypercalcaemic crisis. Arch Surg 1975;110:321-3.

${ }^{11}$ Pezeshki C, Brooker AF. Immobilisation hypercalcaemia. Report of two cases treated with Calcitonin. $J$ Bone and Joint Surg 1977;59A:971-3.

12 Whedon JD, Shorr E. Metabolic studies in paralytic acute anterior poliomyelitis II. Alterations in calcium and phosphorus metabolism. $J$ Clin Invest 1937;36:966-81.

${ }^{13}$ Howard JE. Hypercalcaemia and renal injury. (Edit.) Ann Int Med 1942;16:176.

${ }^{14}$ Deitrick JE, Whedon GD, Shorr E. Effects of immobilisation upon various metabolic and physiologic functions of normal men. Am J Med 1948;4:3-36.

${ }^{15}$ Howard JE, Parson W, Bigham RS Jr. Studies on patients convalescent from fracture: III. The urinary excretion of calcium and phosphorus. Bull John Hopkins Hosp 1945;77:291-313.

${ }^{16}$ Hughes RAC, Newsom-Davis JM, Perkin GD, Pierce JM. Controlled trial of prednisolone in acute polyneuropathy. Lancet 1978;ii:750-3.

${ }^{17}$ Dalakas MC, Engel WK. Chronic relapsing (Dysimmune) polyneuropathy: pathogenesis and treatment. Ann Neurol 1981;9(Suppl): 134-45.

${ }^{18}$ Ashworth B, Smyth GE. Relapsing motor polyneuropathy. Acta Neurol Scand 1969;45:342-50.

19 Thomas PK, Lascelles RG, Hallpike JF, Hewer RL. Recurrent and chronic relapsing Guillain-Barré polyneuritis. Brain 1969;92:589-606. 